\section{EFEITO DE PEDILÚVIO COM SOLUÇÃO DE FORMALINA ASSOCLADO A DESGASTAMENTO DO PISO, SOBRE O QUADRO CLINICO DE PORCAS COM AFECÇOEES PODAIS}

IVO WENT2

Médico Veterinário Faculdade de Medicina Veterinária da UfRGS

JURIJ SOBESTIANSKY

Médico Veterinário

Centro Nacional de Pesquisa de Suínos e Aves - EMBRAPA

PAULO ROBERTO SOUZA DA SILVEIRA Médico Veter inário Centro Nacional de Pesquisa de Surnos e Aves - EMBRAPA

JORGE LUIZ PORTO MUNARI

Médico Veterinário Agropastoril Catarinense

ALFREDO RIBEIRO DE FREITAS Engenhe iro Agrônomo

Centro Nacional de Pesquisa de Suínos e Aves - EMBrapa

WENTZ, I.; SOBESTIANSKY, J.; SILVEIRA, P.R.S.; MUNARI, J.L.P.; FREITAS, A.R. Efeito de pedilúvio com solução de formalina associado a desgastamento do piso, sobre o quadro clínico de porcas com afecçōes podais. Braz. J. ver. Res. anim. Sci., São Paulo, v.28, n.2, p.231-4, 1991.

RESUMO: Com o objetivo de verificar o efeito do tratamento dos cascos com uma solução de formalina a $10 \%$ en pedilúvio associado a diminuição da abrasividade do piso, sobre a melhoria do quadro clínico de porcas com claudicaçōes, foi desenvolvido um experimento envolvendo 102 fèmeas alojadas em 14 baias, com piso parcialmente ripado. As baias, abrigando em média sete animais, foram distribuidas ao acaso em grupo testemunha (T1) e tratado (T2). Os animais do T2 foram submetidos a uma série de 12 passagens por pedilúvio, contendo uma solução de formol a 10\%, distribuídos ao longo de cinco semanas. - piso foi classificado visual e manualmente como muito abrasivo. Através do uso de una lixadeira elétrica procedeu-se à diminuição da abrasividade do piso de todas as baias ( $T 1$ e T2) sendo após classificado como levemente abrasivo. O tratanento com a solução de formalina foi iniciado após correçlo do piso. Para determinar a frequéncia e gravidade das claudicaçōes examinaram-se clinicamente os animais antes do início do tratamento e no final do perfodo experimental. A eficácia dos tratamentos foi medida através do teste do qui-quadrado. Conclui-se que, diminuindo o poder abrasivo do piso, não ocorreu melhora nem agravamento no quadro clínico das claudicaçōes, mas o tratamento com solução de formalina a $10 \%$ promove uma melhora significativa no quadro clínico de claudicaçōes.

UNTERMOS: Claudicaçāo, suínos; Cascos e unhas; Locomoção; Formal ina

\section{INTRODUÇĀO}

Os problemas no aparelho locomotor dos suínos, principalmente aqueles localizados nos cascos, assumem en muitas propriededes proporçōes alarmantes (MARTINEAU-doIze el al. "). Segundo PENAY et al. 10 e SOBESTIANSKY et al. ${ }^{13}$ o desgaste e as lesōes na sola e parede do casco são as alterações mais freqüentemente encontradas. Segundo BOLLWAHN; LAMPE 3 e LAMPE ${ }^{8}$, a freqüência de lesões nos cascos está associada às características do piso. Pisos lisos ou excessivamente rugosos (GONCALVES ${ }^{7}$; PENNY et al. ${ }^{10}$ ), bem como pisos ripados (GEYER ${ }^{5}$ ) tèm marcada influência no desenvolvimento de alterações nos cascos. HRIGHT et al. 15 observaram que pisos muito abrasivos provocaram significativamente mais lesōes moderadas e severas em comparação a pisos pouco abrasivos. PRANGE; BAUMANN 11 observaram percentual de 40,$4 ; 32,1$ e $25,0 \%$ de lesões graves nos cascos respectivamente de animais de abate, fémeas de reposiçăo e leitões em crescimento, criados sobre piso ripado. Estes autores encontraram incidéncias semelhantes a estas, em suínos mantidos sobre piso compacto.

Lesōes nos cascos sob a forma de rachaduras também podem ser encontradas na deficiência de biotina, mas via de regra acompanhadas de outras lesōes na pele (BROOKS et al. ${ }^{4}$; GLATTI ${ }^{6}$; TAYLOR ${ }^{14}$ ).

Para prevenção ou mesmo tratamento de lesões graves nos cascos. PENhY et al. 10 usaram, além do fornecimento de cama, una solução de 5 a $10 \%$ de formalina, empregando WRIGHT et a!. 15, sulfato de cobre ou formal ina a $10 \%$ em pedilúvib, duas vezes por semana, com intervalo de très a quatro cias.

- presente experimento teve como objetivo verificar o efeito do tratamento dos cascos com una 
Efeito de pedilúvio com soluçäo de formal ina associado a desgastamento ...

solução de formalina a 10x, em pedilúvio associado à diminuição da abrasividade do piso, sobre a methora do quadro clínico de claudificações em suínos.

\section{MATERLAL E METODO}

o trabalho foi desenvolvido em uma criação com 1000 matrizes, onde observações preliminares realizadas en 428 fémeas mostraram qu $90,4 X$ apresentavam problemas de claudicaçóes classificadas como leves até muito graves (SOBESTIANKSY et al. 13.).

- experimento envolveu 102 fémeas cruzadas Landrace $x$ Large thite, com 30 a 60 dias de gestaçăo, apresentando claudicaçōes de diferentes graus de severidade, decorrentes de lesões nos cascos. As fémeas foram alojadas em 14 baias de $2,75 \times 5 \mathrm{~cm}$ com piso parcialmente $r$ ipado.

- piso das baias foi inicialmente examinado visual e manualmente e classificado, de acordo com PENNY et al. 10 , como muito abrasivo. Através de uma lixadeira elétrica" procedeu-se à diminuição da abrasividade do piso em todas as baias. As baias, abrigando em média sete animais, foram distribuidas, ao acaso, em dois grupos: testemunha (T1) e tratado (T2). Os animais do TI permaneceram durante o período experimental sobre o piso lixado, enquanto os animais do 12 foram submetidos a una série de 12 passagens por um pedilúvio, contendo uma solução de formal ina a 10\%, por um período de cinco semanas, com três tratamentos semanais nas duas primeiras semanas e dois nas très semanas subseqüentes.

Para determinar a freqüencia e gravidade das claudicaçōes antes do início do tratamento e no final do perfodo experimental, os animais foram examinados clinicamente segundo método de diagnóstico clínico de claudicações de suínos, descrito por BoLlWAHM 2 e SCHULZE ${ }^{12}$.

A inspeção foi realizada com os animais parados e em movimento, nas baias e no corredor da instalaçäo. As claudicaçōes foram classificadas de acordo com a gravidade em: Grau 1 = discreta: alterações discretas no andar do animal e alternância no apoio dos membros quando parado; Grau 2 = médias: distúrbio locomotor perfeitamente perceptível no andar do animal e, quando parado, alteração no apoio e na posição do membro; Grau 3 = grave: alteração grave no deslocamento; o animal apoia o membro com dificuldade; Grau 4 = muito grave, o animal procura permanecer deitado, levanta com dificuldade e dificilmente apoia o membro comprometido. Para fins de classificação, quando um animal claudicava em mais de um membro simultaneamente, considerou-se somente a claudicaç⿰o mais grave.

Os resultados foram analisados através do teste de qui-quadrado.

\section{RESULTADOS E DISCUSSÄO}

A Tab. 1 mostra a distribuição das fémeas de acordo com a gravidade de claudicaça nos tratamentos, antes e após o perf́odo experimental, bem como o número de fêmeas el iminadas.

Observou-se una alta freqüencia de claudicações nos dois grupos ( $T 1=96 \%$ e $T 2=98 \%$ ) antes do período experimental. No grupo $T 1$ houve predominancia de claudicaçōes de grous médio $(44,0 x)$ e grave $(36,0 \%)$ enquanto no grupo T2 a predominância foi respectivamente dos graus grave $(34,6 \%)$ e médio $(32,7 x)$, não havendo, porém, diferença estatística significativa entre os mesmos $(P>0,05)$. Em outros levantamentos realizados ao nível de granja, a incidéncia e gravidade das claudicaçōes em suínos tên sido relativamente altas (PENMY et al. 10 e PRANGE; BAUMANN ${ }^{11}$, e, segundo MARTINEAU-DCIZE et al. " podern assumir caráter epidêmico.

No presente estudo, o piso utilizado foi considerado muito abrasivo causandc, provavelmente, lesōes nos cascos em un grande número de animais, aparecendo as claudicações em diferentes graus de sever idade.

Um possivel envolvimento da biotina foi descartado, una vez que, ao exame clínico, os reprodutores não apresentaram, além das lesões nos cascos, outros sintomas descritos por BROOKs et al. 4 ; GLATTI 6 ; TAYLOR 14 como características de deficiência de biotina.

Após passar a lixadeira sobre o piso, o mesmo foi classificado como levemente abrasivo. Segundo BOLLWAHN; LAMPE ${ }^{3}$ o piso deve apresentar un certo grau de abrasividade para que o suíno adquira firmeza ao andar sobre o mesmo. Da mesma forma, un certo grau de abrasividade é necessário para haver um desgaste natural do casco, pois, segundo GEYER ${ }^{5}$, apresenta um crescimento de 5 a 6 mm por més. Uma vez que a Lixadeira foi passada tanto sobre o piso do grupo testemunha como do grupo tratado, poder-se-ia inferir que os resultados obtidos estariam relacionados com $a$ eliminaçăo da abrasividade do piso e não com o tratamento com formalina. No entanto, anal isando os resultados obtidos (Tab. 1) verifica-se que no grupo testemunha, onde somente foi eliminado a causa (piso abrasivo), não houve un agravamentc do auadro clínico das claudicações, enquanto que, ne grupo tratado, houve significativa melhora.

* Modelo $20 \mathrm{n}^{2} 657$ - Equiplan S.A. 
Efeito de pedilúvio com solução de formalina associado a desgastamento ...

Estes resultados sugerem que o piso abrasivo certamente um fator predisponente para instalaçăo de lesão no casco e, em maior grau, teria un papel como fator determinante. Quando se associou o pedilúvio, diminuiu sobremaneira a freqüência do problema, sugerindo que existe outro fator determinante de grande influéncia sobre o desencadeamento da doença, provavelmente de origem bacteriana. BLAHA; PRANGE afirman que, com a adoção de medidas curativas nos cascos, somente podem ser obtidos resultados positivos quando as causas das alteraçōes forem el iminadas. A diminuição da abrasividade do piso através da lixadeira, ou outros métodos, tem como finalidade mais importante diminuir o desgaste excessivo do casco, parede córnea e almofada plantar, eliminando, desta forma, a principal causa da instalaçäo das lesōes.

Por outro lado, observa-se na Tab. 1 que, após 5 semanas de tratamento ocorreu, no grupo tratado (T2), um aumento significativo ( $P<0,05)$ na percentagem de animais sem claudicaçăo, de 1,9 para $40,0 \%$, bem como una diminuiça significativa do percentual de animais com claudicaçao grave, de $34,6 \%$ para $9,6 \%$. Quanto à eliminação, observou-se un menor percentual de animais eliminados por problema de claudicaçăo no grupo tratado $(5,8 \%)$ comparado ao testemunha $(14,0 \%)$. Foram el iminados os animais que apresentaram claudicações muito graves, com lesões profundas en um ou mais cascos, formação de flegmão e, conseqüentemente, dificuldade de levantar e deslocar-se. Resultados semelhantes foram obtidos por PENAY at al. 10 em várias granjas com problemas graves de claudicaçōes. Em uma destas granjes, na qual, além da passagem em pedilúvio com formol a 10\%, PENNY et al. 10 recomendaram a colocação de uma camada de palha sobre - piso áspero, e observaram uma melhora acentuada já em dez dias do inicio do tratamento.

A formalina por sua vez, além de agir como antisséptico local em lesōes com contaminaçăo bacteriana, tem a propriedade de endurecer os tecidos através do processo de desnaturação das proteínas, diminuindo ou eliminando, dessa forma, o quadro clínico da claudicação (MARTINEAU-DoIZE et al. 9 ).

\section{CONCLUSOES}

1- A diminuição da abrasividade do piso não acentua o quadro clínico das porcas com claudicação;

2- 0 uso de pedilúvio com solução de formalina, associado a redução da abrasividade do piso, melhora o quadro clínico de porcas com afecções podais.
MENTZ, I.; SOBESTIANSKY, J.; SILVEIRA, P.R.S.; MUNARI, J.L.P.; FREITAS, A.R. The effect of formalin solution in footbath associated with floor abrasiveness reduction on clinical aspects of lameness in sows. Braz. J. vet Res. anim. Sci., São Paulo, v.28, n.2, p.231-4, 1991.

SUMMARY: An experiment was made in order to evaluate the effect of hooves treatment with $10 \%$ formal in solution in a footbeth plus a recuction in the floor abrasiveness on the clinical aspect of lameness. One hundred and two sows, in 14 boxes with partially slatted floor, were used. The animals, seven in each box, were randomly divided in control (T1) and treatment (T2), where the animals were submitted to 12 passages in a $10 \%$ formal in in solution footbath during five weeks. The box floor was visual and manually classified as a very abrasive. Afterwards using an electric sharper the floor of all the boxes was polished and it was then classified as milddy abrasive. The treatment (T2) started after the floor correction. The animals were clinically examined in order to evaluate lameness frequency and severity at the beginning and at the end of the experiment period. The results were compared by qui-square test. It was concluded that with the decrease of the floor abrasiveness there was no improvement of the clinical situation of lameness but it is not worse and that the treatment with $10 \%$ formalin solution reduce significantly the lameness.

UNTTERMS: Lameness, pig; Hoof and claw; Locomotion; Formal in

\section{REFERENCLAS BIBLIOGRÁFICAS}

01-BLAHA, T.; PRANGE, H. Untersuchungen zur Klaue-und $\mathrm{Gl}$ iedmassengesundhe it be $\mathrm{i}$ Besamungsebern. $\mathrm{Mh}$. Vet.Med., v.30, p.47-53. 1975.

02-BOLLWAHN, E. Klinische Diagnostik der Lahmheuen beim Schwein unter besonder Bernueksichtigung der Roentgenuntersuchung. Hannover, 1975. Tese (Livre Docència) - Tierarztliche Hochschule.

03-BOLLWAHN, W.; LAMPE, M. Beziehungen zwischen Stallboden und Klauenwachstum bei Schweinen. Tierärzl. Umsch., v.35, p.326-32. 1980.

04-BROOKS, P.H.; SMITH, D.A.; IRVIN, V.C.R. Biotin supplementation of diets; the incidence of foot 
Efeito de pedilúvio con soluçăo de formalina associado a desgastamento ...

lesions and the reproductive performence of sows. Vet. Rec., v.101, p.44-50, 1977.

05-GEYER, H. Morphologie und Wechroum der Schweineklaue. Zurich, 1979. Tese (Livre Docência). Veterinarmedizinische Fakultat der Universitat. Zur ich.

06-GLATTI, H.R. Zur Klinik des experimentell erzeugten Biotinmangels beim Schwein und Mitteiling erster Ergebnisse aus Feldversuchen. Schweiz Arch Tierheilk., v.117, p.135-44, 1975

07-GONÇALVES, P.R. Der Einfluss verschiedenet Stallbodenoberflachen auf das Hornwachsum und der Abrieb sowie die Gesundheis der Klawen von Zuchusauen. Hannover, 1981. Tese (Doutorado) Tierarztlichen Hochschule.

08-LAMPE, M. Der Einfluss verschiedener Stallbodenoberflaechen auf das Hornwachstum und Abrieb sowie die Gesundheir der Klawen von Mastschweinen. Hannover, 1978. Tese (Doutor ado) - Tierarztliche Hochschule.

09-MARTINEAU-DOIZE, B.; MARTINEAU, G.; BIENFAIT, J.M.; DEWAELE, A. Lesions podales chez le porc cause et consequences. Ann. Med. ver., v.123, p. $469-75,1979$.
10-PENMY, R.H.C.; OSBORME, A.D.; WRIGHT, A.I.; STEPHENS, T.K. Foot-rot in pigs: observations on the clinical disease. Ver. Rec., v.75, p.1101. 8, 1965.

11-PRANGE, H.; BALMANN, G. Beziehungen zwischen Fussbodengestaltung und Gl iectnassengesuncthe it in der Modernen Schwe inehal tung. Mh. Ver.Med., v.27, p.416-23, 1972.

12-SCHULZE, $\mathbf{H}$. Kl inische Untersuchungen. In: SCHULZE, W.; BICKHARDT, K.; BOLLWAHN, W.; MICKWITZ, G.; PLONAIT, H. Klinik der Schweinekrankheiven. Hannover, M. \& Schaper, 1980. p.3-32.

13-SOBESTIANSKY, J.; WENTZ, I.; SILVEIRA, P.R.S.; MUNARI, J.; FREITAS, A.R. Ocorrência e caracterizaçáo das lesōes nos cascos de fémeas suínas reprodutoras. Rev. Fac. Med. Vel Zootec. Univ. S. Paulo., v.26, p.235-40, 1989.

14-TAYLOR, D.J. Pig disease. 4.ed. Cambridge, Berlington Press, 1986.

15-WRIGHT, A.I.; OSBORNE, A.D.; PENMY, R.H.C.; GRAY, E.M. Foot-rot in pigs: experimental production of the disease. Vet Rec., v.90, p.93-9, 1972.

TABELA 1 - Distribuição dos animais de acordo com o grau de claudicação nos grupos testemunha (Tq) e tratados com formalina a $10 \%$ (T2) em pedilúvio e respectivo número de fémeas eliminadas durante a fase experimental.

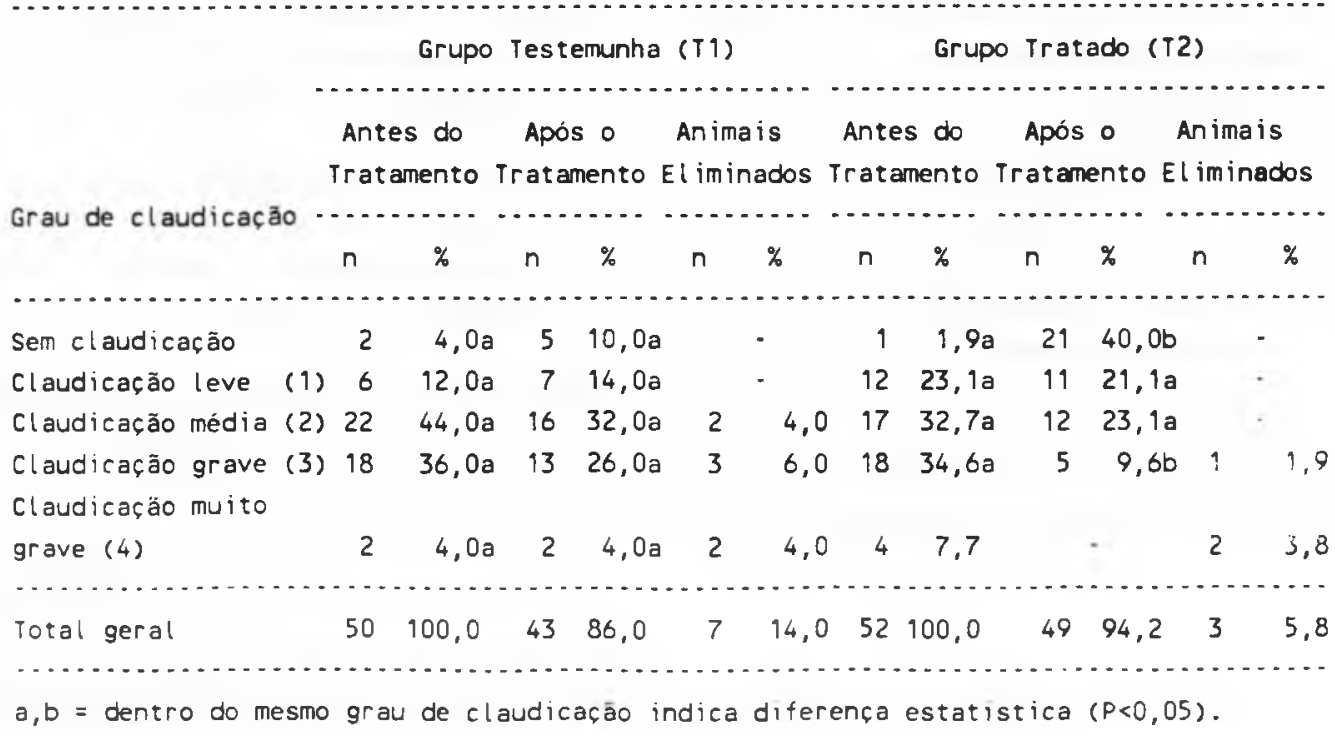

